\begin{tabular}{|r|r|r|r|r|r|}
\hline MUNIBE Antropologia-Arkeologia & $n^{\circ} 70$ & $319-334$ & DONOSTIA & 2019 & ISSN $1132-2217 \bullet$ elSSN 2172-4555 \\
\hline
\end{tabular}

\title{
Los materiales arqueológicos de la fortaleza de Mendikute, Gipuzkoa (s. XII-XIV): elementos para el estudio de la vida cotidiana en un asentamiento militar
}

\author{
Archaeological materials from the fortress of Mendikute \\ $\left(13^{\text {th }}-14^{\text {th }}\right.$ Centuries) (Gipuzkoa, Basque Country): \\ Elements for the analysis of daily life in a military settlement
}

PALABRAS CLAVES: Castillo, cerámica, metal, hueso, armamento, ornamentación.

GAKO-HITZAK: Gaztelua, zeramika, metala, hezurra, armamentua, apaingarriak.

KEY WORDS: Castle, pottery, metal, bone, weaponry, embellishment.

Karen ALVARO(1) y Esther TRAVÉ(1)

\section{RESUMEN}

Las excavaciones llevadas a cabo a finales de los noventa en la fortaleza medieval de Mendikute (Gipuzkoa) permitieron recuperar un amplio conjunto de materiales arqueológicos representativos de la actividad cotidiana de un asentamiento militar de frontera. Entre ellos se documentan algunos materiales cerámicos, abundante material óseo y un amplísimo repertorio de elementos metálicos, preferentemente férricos pero también de bronce. El conjunto de metales de Mendikute permite ilustrar algunos de los elementos propios del armamento bajomedieval y de los enseres de carácter ornamental que componen la vestimenta propia de la soldadesca. Este trabajo presenta una visión de conjunto de todos ellos a fin de definir los principales rasgos de los restos de material mueble de este asentamiento fortificado y su trascendencia para el estudio de la vida cotidiana de una guarnición de frontera.

\section{LABURPENA}

Mendikuteko (Gipuzkoa) Erdi Aroko gotorlekuan 1990eko hamarkadaren azkenetan egindako indusketa-lanei esker, material arkeologikoen multzo eder bat berreskuratu zen, mugako asentamendu militar bateko eguneroko jardunaren berri ematen duena. Horien artean dokumentatzen dira, konparazio batera, zeramikazko materialak, hezur-material ugari eta metalezko elementuen errepertorio zabal bat -gehientsuenak burdinazkoak, baina badira brontzezkoak ere-. Mendikuteko metalen multzoak Behe Erdi Aroko armamentuan baliatutako zenbait elementuren berri ematen digu, eta garai hartako soldaduen jantzien apaingarriak ere erakusten dizkigu. Lan honen bidez, elementuon guztion ikuspegi bat aurkezten da, asentamendu gotortu horretako material higigarrien hondarren ezaugarri nagusiak definitzeko; orobat, azaltzen da material horrek zer garrantzi duen mugako garnizio baten eguneroko bizitza aztertzeko.

\section{ABSTRACT}

During the archaeological fieldwork carried out during the latest nineties at the medieval fortress of Mendikute (Gipuzkoa, Basque Country) a vast amount of archaeological materials representative of daily activities in a military border settlement was discovered. Amongst these, some pottery, abundant bone pieces and a vast repertoire of metallic elements were included. The metal assemblage from Mendikute, preferably iron but also bronze, includes some of the characteristic elements of late medieval weaponry and some pieces for soldiers clothes embellishment. This paper introduces a summary view of these materials in order to define the main features of mobile material remains at this fortified settlement and their relevance for the study of daily life in a border fortress.

\section{INTRODUCCIÓN}

Las investigaciones arqueológicas llevadas a cabo en la fortaleza medieval de Mendikute se desarrollan desde 1992 y durante seis campañas arqueológicas bajo la dirección de J. I. Padilla, en el marco de un proyecto de investigación centrado en la estructura del poblamiento y la organización social del espacio guipuzcoano en la cuenca alta del río Oria. El objetivo principal de los trabajos realizados en este ámbito aspiraba a conocer con mayor precisión las características propias de la configuración histórica de un territorio singular a partir de las fuentes materiales, dada la escasez documental con que

\footnotetext{
(1) Grup de recerca d'arqueologia medieval i postmedieval. Dept. de Història Medieval, Paleografia i Diplomàtica.Universitat de Barcelona. C/ Montalegre n6-8, 08001 Barcelona. E-mail: kalvaro@ub.edu; esther.trave@ub.edu
} 
contamos para esta área en los primeros siglos medievales. Dicho proyecto, que se inició con la excavación de Mendikute, permitió llevar a cabo un análisis en clave territorial a partir del cual se intervino en el yacimiento cercano de Ausa-Gaztelu (Zaldibia), y se prospectaron las fortalezas de Aitzorrotz (Escoriaza), Jentilbaratza (Ataún) y Beloaga (Oyartzun), junto con algunos otros lugares relacionados con el estudio del territorio como el camino de San Adrián, paso de frontera entre Álava y Guipúzcoa, entre otros enclaves.

Las fuentes materiales, cuyas evidencias son claras en el territorio, constituyen un elemento fundamental para el conocimiento de un proceso histórico complejo, centrado en la articulación de un espacio de frontera. La excavación de Mendikute permitió elaborar un registro arqueológico de calidad (PADILLA, 1992-7) que dibuja las principales líneas de ocupación del asentamiento y que aporta valiosa información del mismo, a pesar de los procesos de reutilización posterior, especialmente durante el periodo inicial de la Guerra Civil Española. El conjunto de materiales recuperados constituye un valioso testimonio para el conocimiento de la vida en estas guarniciones de frontera, que controlaban un espacio fronterizo entre los reinos de Navarra y Castilla.

El proceso de estudio del registro arqueológico y el considerable volumen de materiales recuperados prolongó las investigaciones a lo largo de los años noventa y de la primera década del presente siglo. El hallazgo de algunas evidencias numismáticas en el asentamiento nos lleva a proponer para el mismo una horquilla cronológica comprendida entre los siglos XII y XIV; a pesar de que el origen de la formación podría remontarse tal vez al siglo $\mathrm{XI}$, a tenor de las informaciones documentales más antiguas para la provincia de Guipúzcoa. En un documento datado en 1025 se recoge una referencia directa sobre el topónimo Albiztur e indirecta sobre la fortificación (UBIETO, 1963).Actualmente nos encontramos en condiciones de ofrecer una aproximación conjunta al volumen de materiales de época medieval descubiertos en el yacimiento de Mendikute. En este trabajo proponemos una primera sistematización de los mismos, ofreciendo una panorámica de conjunto y definiendo las estrategias futuras para aproximarnos al análisis de un valioso conjunto que debe ser objeto de una caracterización pormenorizada.

Ciertamente, los recientes avances en arqueología medieval nos permiten aproximar-nos al conjunto desde una perspectiva renovada. Las distintas propuestas sobre cuantificación (ADROHER et alii, 2016) y análisis morfométrico (MAURI et alii, 2012), especialmente aplicadas al material cerámico pero exportables a conjuntos muy diversos, unidas a los avances técnicos en los procesos de documentación genérica de los materiales, nos permiten abordar el estudio del conjunto de Mendikute con un afán multidisciplinar y con el objetivo de que la caracterización adecuada de los mismos permita dar respuesta a las cuestiones inherentes a su cronología, probable origen y trazas de utilización.
Los materiales que presentamos en este trabajo constituyen un repertorio variado que incluye elementos propios del vestido, de las actividades constructivas y bélicas, y que atestigua, además, las evidencias materiales de otras actividades cotidianas como la alimentación o el empleo del tiempo de ocio. El presente artículo contempla una cuantificación y caracterización preliminar del conjunto de artefactos recuperados, que constituyen un elemento de reflexión destacado para el conocimiento de estos espacios de frontera y la configuración del territorio guipuzcoano.

\section{LA FORTALEZA DE MENDIKUTE}

La fortaleza de Mendikute (Albiztur, Guipúzcoa), fue erigida sobre las estribaciones del monte Ernio, entre los valles guipuzcoanos de los ríos Oria y Urola. Su emplazamiento se localiza entre las cimas y el valle, situado en una de las formaciones calizas más abruptas del entorno. La posición privilegiada que ocupa esta fortificación le permitió a lo largo de distintos periodos de la historia controlar el espacio de manera muy efectiva, ya que domina visualmente un vasto panorama que se extiende al sudeste hasta la sierra de Aralar (MARTINENA, 1994). La toponimia del yacimiento arqueológico de Mendikute, situado en la cumbre del monte homónimo, nos sugiere una cierta fosilización de la terminología latina. El topónimo significa monte (eusk. Mendi-) agudo (lat. -acatus) (AROCENA, 1957: 313-315). La traducción al euskera de una parte del topónimo no parece una formulación excesivamente tardía, puesto que se hubiera adoptado la fórmula Mendizorrotz en ese caso (MITXELENA, 1953: 92), por lo que la antigua denominación latina parece haberse mantenido, al menos en parte. La presencia cercana del topónimo Akatu, que designa un montículo al oeste de Mendikute en el municipio de Vidania, parece ratificar dicha hipótesis.

La fortificación de Mendikute destaca por su simplicidad y reducidas dimensiones, al igual que otros emplazamientos coetáneos como el caso de Beloaga (Oyarzun), Ausa-Gaztelu (Zaldibia), Jentilbaratxa (Ataun), Aitzorrotz (Escoriaza), Goikobalu (Mondragon) y Elosua (Bergara) (Fig. 1). Responden todos ellos, y en particular Mendikute, a la construcción clásica de los castillos roqueros, que siguen unas mismas pautas de diseño simple a la par que eficaz, aprovechando la conformación natural de un peñasco y adaptando sus estructuras defensivas a la orografía de los afloramientos rocosos de cada emplazamiento. La fortaleza de Mendikute, que se encuentra a una altitud de 814 metros sobre el nivel del mar, está compuesta por dos ámbitos escalonados bien definidos y asentados sobre el suelo rocoso que acaba definiendo el perímetro defensivo tanto inferior como superior. Este espacio distribuido en dos niveles nos permite definir un recinto noble al que se accede desde un recinto inferior, probablemente destinado a caballerizas (Fig. 2). 


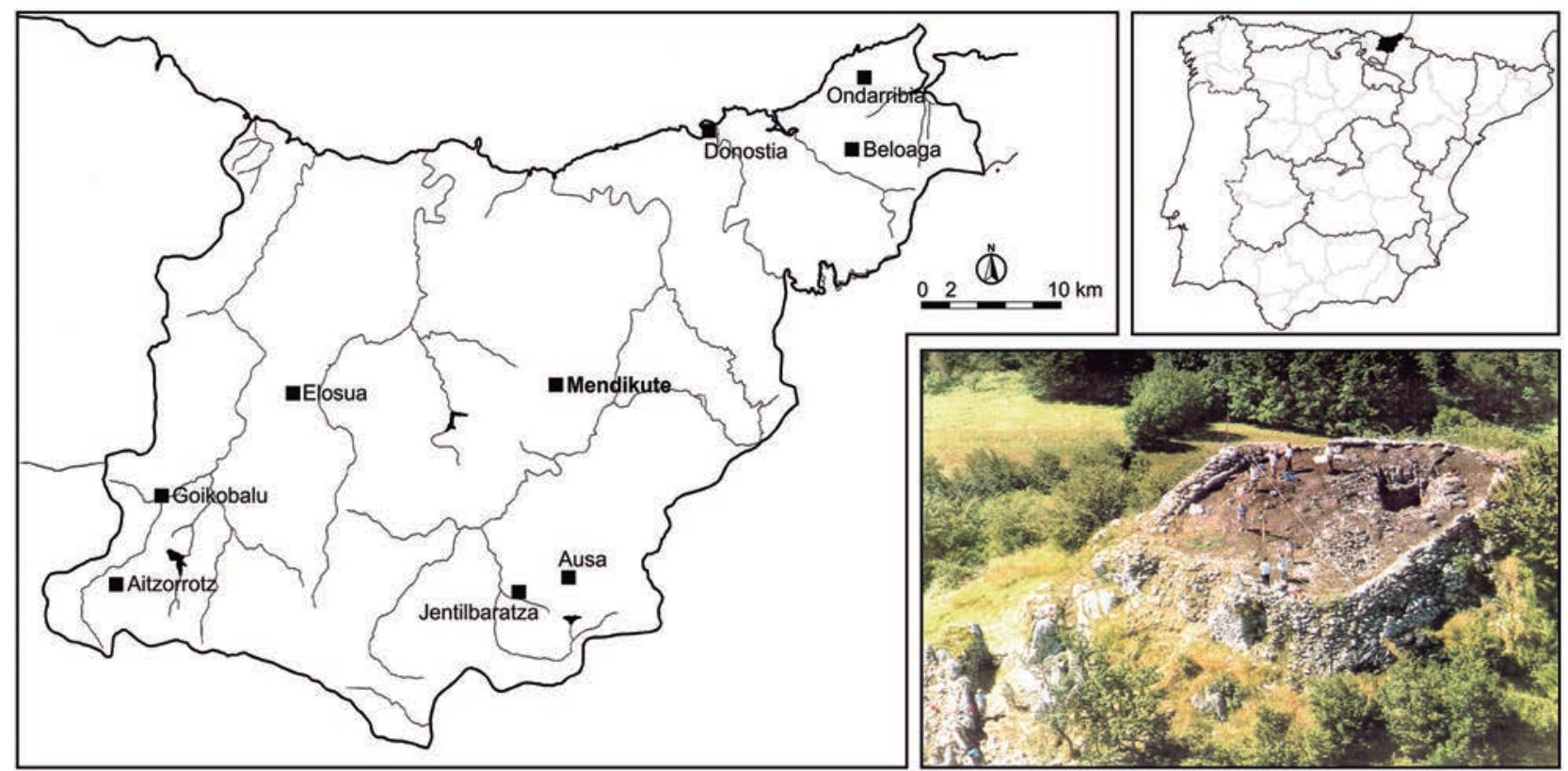

Fig. 1. Mapa de la provincia de Gipuzkoa con la localización de las fortalezas medievales, entre las que se cuentan el yacimiento de Mendikute. / Map of the province of Gipuzkoa where the medieval fortress of Mendikute among others is located.

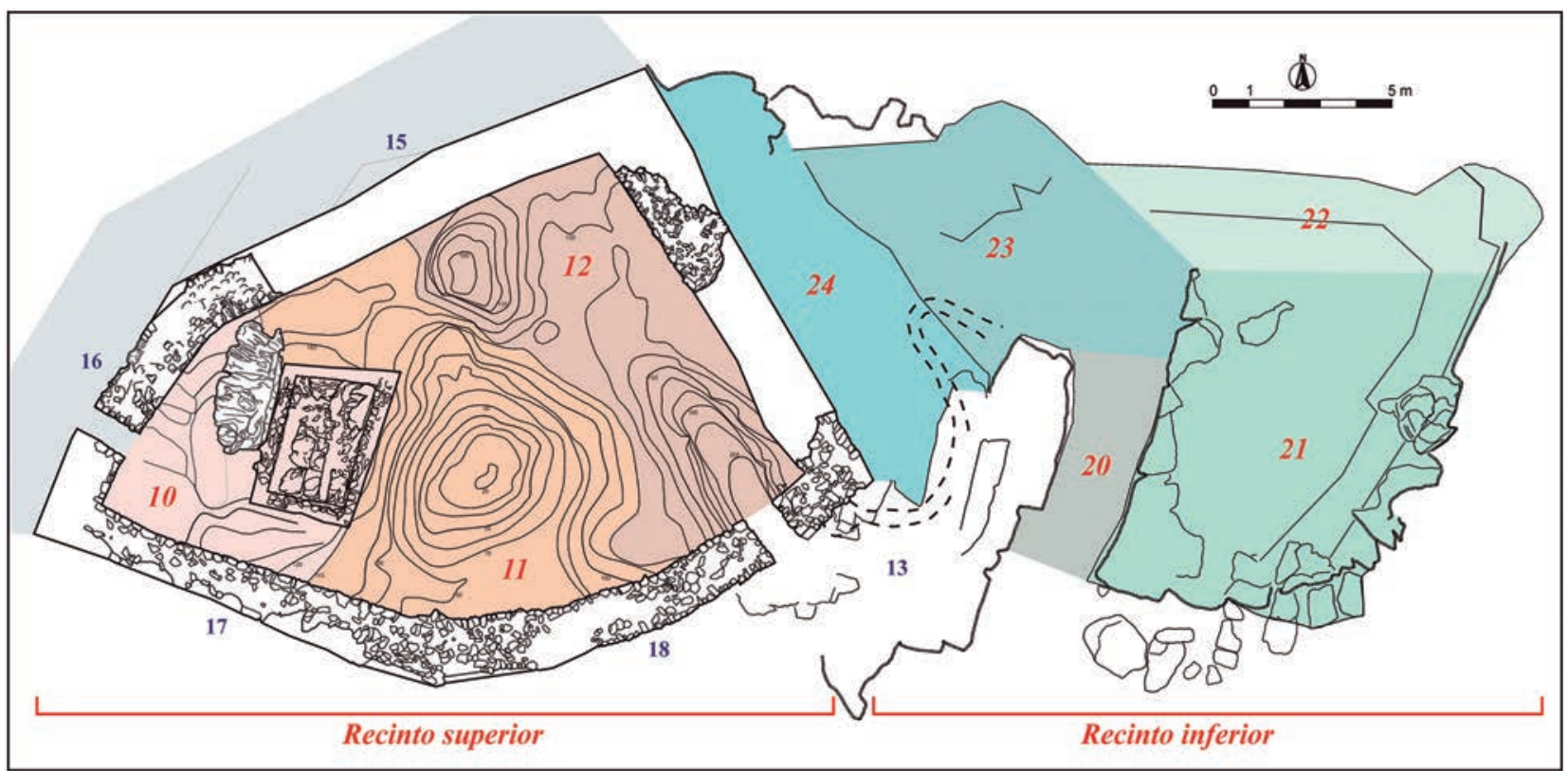

Fig. 2. Planta general de la fortificación con indicación de los recintos superior o noble e inferior y de los sectores intervenidos al interior y al exterior de ambos. / Plan layout of the fortress. Location of upper (or noble) and lower enclosures are indicated together with the excavated trenches inside and outside both areas.

El cuerpo superior de la fortificación es una construcción de planta poligonal en forma de heptágono irregular, perfectamente adaptado a la plataforma rocosa sobre la que se asienta (Fig. 3). Este recinto noble presenta una cisterna rectangular (Fig. 4a) en la zona oeste y aparece delimitado por muros de mampostería a base de sillarejo aparejado en ambas caras. Esta estructura murada se utiliza también en el recinto inferior, donde el espacio además aparece flanqueado por baluartes (Fig. 4b). La simplicidad de la estructura arquitectónica contrasta con la complejidad estratigráfica propia de los espacios reutilizados o frecuentemente intervenidos.

Con anterioridad al proyecto de investigación desarrollado durante los años noventa por el equipo de investigación en arqueología medieval de la Universidad de Barcelona, el emplazamiento sufrió dos intervenciones anteriores que lo afectaron en gran parte. Los tra- 

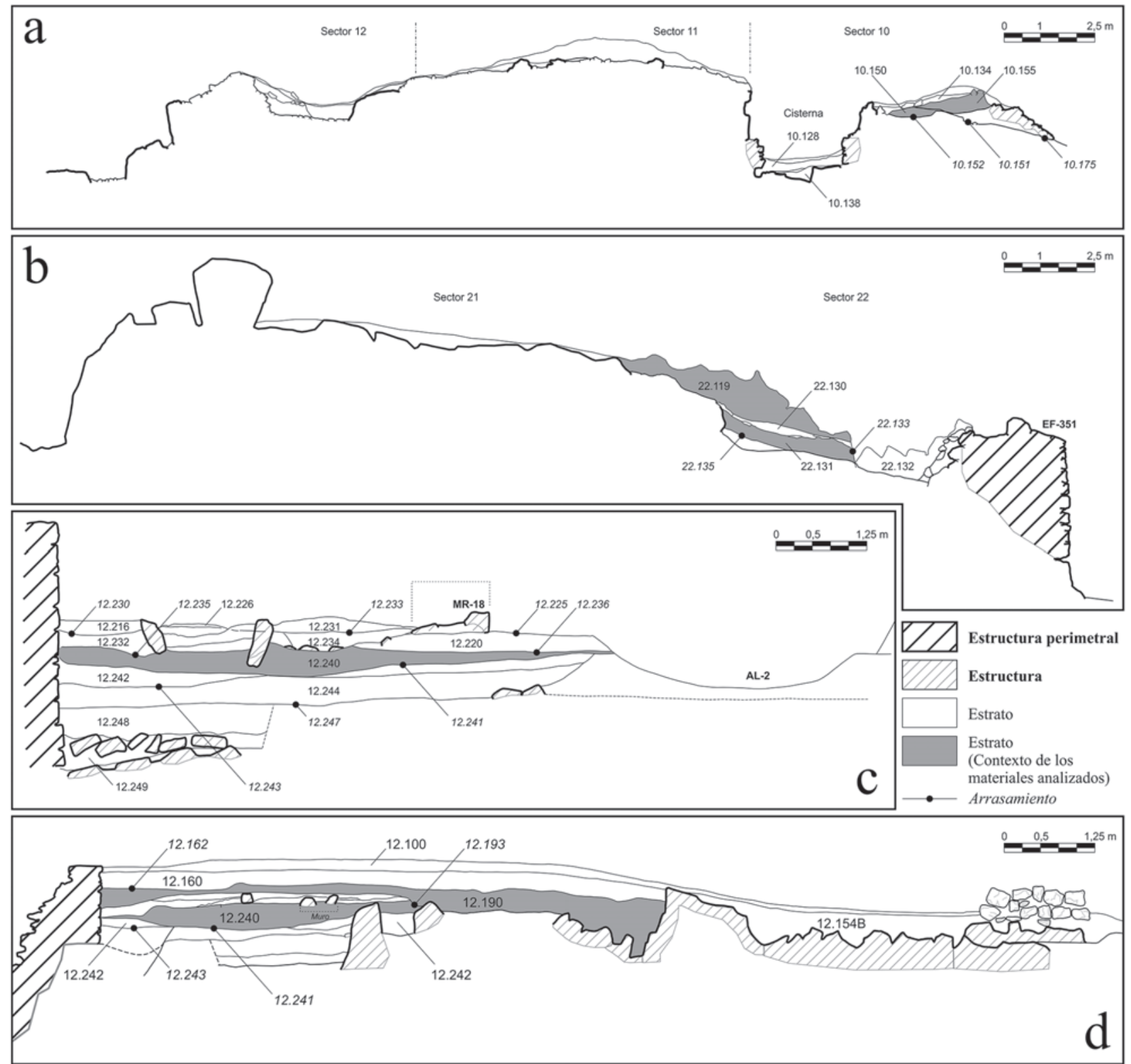

Fig. 3. Vista aérea del conjunto desde el nordeste, donde se aprecia la mayor parte de los recintos murados que componen la fortificación. El aspecto general del recinto noble habla por sí mismo del estado de conservación y de los graves problemas de consolidación que presentan las estructuras defensivas de este yacimiento (1993). / Aerial view of the fortress taken from the north-east, where most of the walled-rooms can be perceived. The general overview of the noble enclosure evidences the serious consolidation problems of the defensive structures in this site (1993).

bajos realizados en 1911 por I. Mendizabal y E. Retondo tuvieron un impacto considerable sobre los niveles medievales del yacimiento. Al margen de estas intervenciones tempranas, durante el periodo inicial de la Guerra Civil (1936 - 1937) el recinto fue ocupado, por lo que se llevaron a cabo alteraciones muy significativas de los niveles más antiguos. A ello se añaden algunas actividades clandestinas que contribuyeron también a la afectación sustancial del depósito arqueológico más antiguo del yacimiento. Estas circunstancias obligaron a desarrollar los trabajos arqueológicos con gran cuidado y escrupulosa atención a la hora de construir la secuencia estratigráfica. Sólo así fue posible docu- mentar con precisión las sucesivas alteraciones y la inversión de depósitos con la afectación que ello supone para recuperar el contexto de los materiales hallados.

A pesar del estado de conservación más o menos precario y de los procesos de afectación posterior que estos yacimientos hayan podido experimentar, las fortalezas del Alto Oria constituyen un elemento emblemático para el conocimiento del periodo comprendido entre los siglos XI y XIII. Esta etapa, se ha considerado tradicionalmente el periodo de formación histórica de Guipúzcoa (BARRENA, 1989) dada la trascendencia de los acontecimientos que se desarrollan en este momento. En este contexto, las fuentes arqueológicas de- 

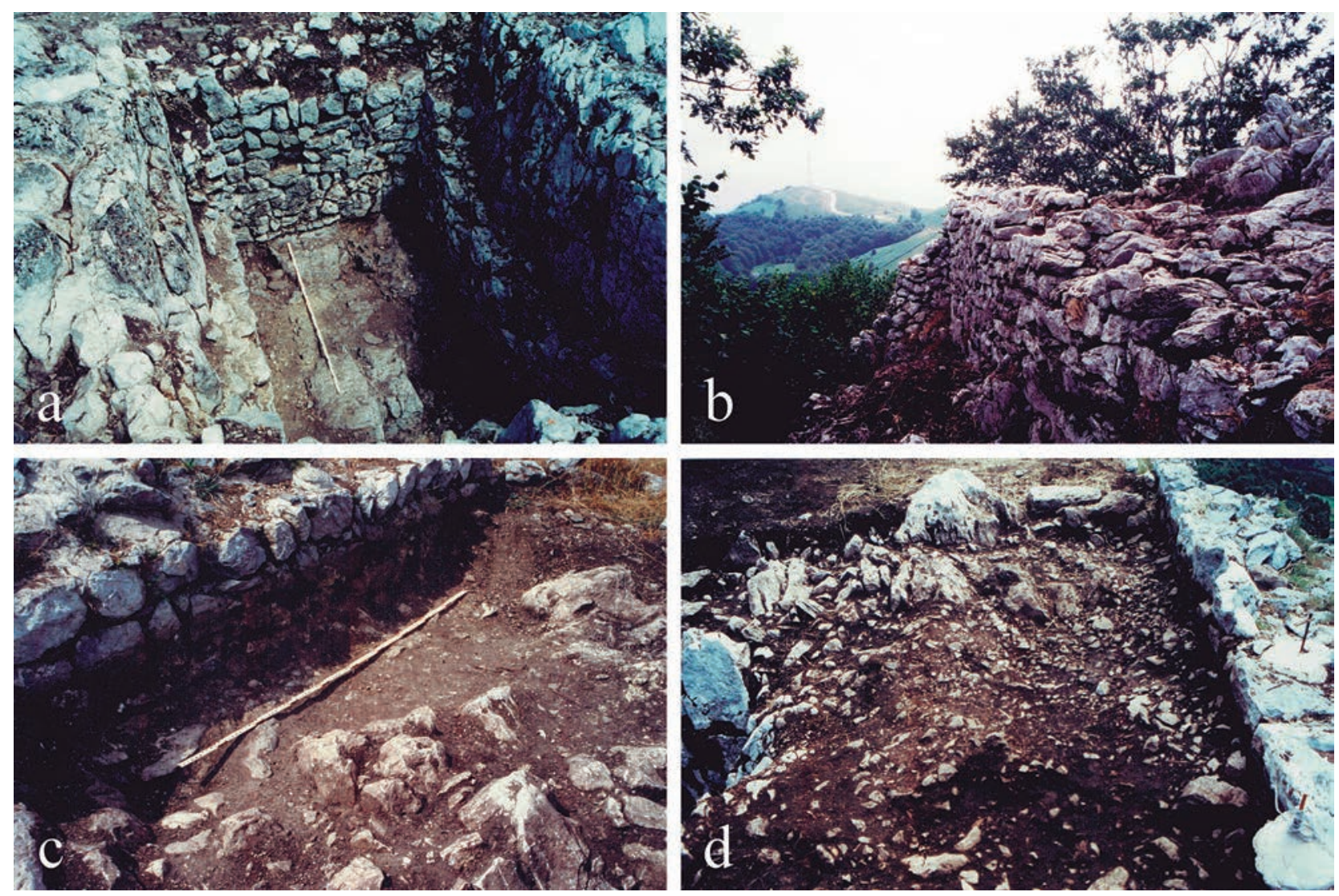

Fig. 4. Distintas vistas de la fortaleza de Mendikute: (a) Cisterna del recinto noble tras su excavación y limpieza en 1994, (b) vista del muro septentrional y de los restos de uno de los baluartes que guarnecen el recinto inferior del conjunto castral, (c) detalle del área meridional del sector 11 en donde la muralla se asienta sobre la base rocosa del emplazamiento en 1995, y (d) aspecto del área meridional del sector 10 tras la extracción de los niveles superficiales./ Different views of the Mendikute fortress: (a) Cistern in the noble area after its excavation and cleaning in 1994; (b) view of the northern wall and the remains of an archer tower protecting the lower enclosure of the fortress; (c) detail view of the southern area of trench 11, where the wall rests upon the bedrock, in 1995; and (d) overview of the southern area of trench 10 after the excavation of superficial level.

vienen un elemento imprescindible para el conocimiento de un periodo para el que todavía debe advertirse una relativa escasez de las fuentes documentales, que apenas nos aportan informaciones sobre esta etapa en el espacio social guipuzcoano.

Con anterioridad al siglo XI no disponemos prácticamente de datos fiables para hablar de una realidad histórica guipuzcoana y las lagunas existentes en el conocimiento de la organización social primitiva de este espacio son considerables. Aun así, a lo largo de los siglos XI y XII se asiste a una transformación social, en que las antiguas formas organizativas del territorio sufren el inicio de un proceso hacia modelos de control territorial propios del sistema feudal, en el que los tenentes navarros y castellanos tratan de imponer su dominio sobre el área a través del control de las estructuras de dominio antiguas. Estas influencias junto a otros fenómenos altomedievales que afectan al territorio, como el proceso de cristianización por ejemplo (AZKARATE, 1988; 2005), han sido estudiados por algunos historiadores como parte de un "proceso de aculturación de estilo mediterráneo" que afecta a gran parte del norte peninsular, y que acabaran por transformar las estruc- turas sociales antiguas en nuevas formas organizativas (BARRENA, 1989).

El espacio histórico que hoy configura el área guipuzcoana nace como consecuencia de estas transformaciones y consolida su carácter territorial durante el siglo XIII, a través de una reorganización de su antiguo poblamiento en villas de creación más tardía y que constituyen una nueva forma de organización social, que surge en contraposición a las fuerzas organizativas dominantes del pasado. De esta forma, el carácter dinámico de cada una de las realidades históricas que engloba el territorio en época medieval son el resultado de la relación dialéctica entre el sustrato gentilicio antiguo y las pretensiones señoriales y, entre estas pretensiones y la dinámica propia de la reorganización social que da origen a las villas.

En este sentido, la evolución histórica de la sociedad guipuzcoana no parece seguir los mismos ritmos que dominan la historiografía europea. Esta situación tampoco es un hecho casual en tanto que Guipúzcoa conforma un espacio marginal con un cierto carácter periférico, como sucede en tantas otras áreas del espacio peninsular y el continente europeo (GARCÍA DE CORTÁZAR, 1988). Las transformaciones de los siglos 
XI y XII, que operan sobre la sociedad guipuzcoana, siguen un ritmo propio que definen la plenitud medieval como resultado de unos condicionamientos específicos que engloban un precedente altomedieval con una idiosincrasia particular (BARRENA, 1989).

En este contexto, se desarrolla la pugna entre las monarquías navarra y castellana por atraer bajo su dominio este territorio. Las oscilaciones políticas propias de este espacio condicionan las transformaciones que acabarán por definir una nueva articulación territorial de manera lenta y no siempre fácil. El cambio viene dado por un proceso de jerarquización cuyo desarrollo acabará por definir un nuevo orden social, acompañado de una profunda reorganización territorial. Estas circunstancias originan en un momento en que aparecen las primeras menciones documentales de "Ipuzcoa". Es en este momento cuando las fortificaciones adquieren pleno significado ya que constituyen el símbolo y marca identitaria de señores que fortalecen su dominio en el seno de un nuevo orden político, y a su vez se transforman en elementos jerárquicos a partir de los cuales se reordenan el territorio y sus poblaciones. En este contexto, la fortificación medieval de Mendikute constituye un claro ejemplo de los elementos protagonistas de este proceso de reordenación territorial, que se manifiesta bajo diferentes fórmulas respecto a otros territorios peninsulares.

La fortaleza consta de dos recintos escalonados con características propias y funciones bien diferenciadas, tal como hemos tenido ocasión de comentar anteriormente. Dichos espacios fueron subdivididos internamente a efectos organizativos de las tareas de excavación y a fin de facilitar los trabajos de registro. Así, se definieron como recintos fortificados superior e inferior y como áreas no fortificadas los entornos inmediatos al recinto amurallado donde también se procedió a la excavación y registro, así como la recuperación de determinados materiales. En el seno del recinto noble, se determinaron tres sectores $(10,11$ y 12) que corresponden al ámbito occidental, central y oriental del recinto respectivamente, siendo el ámbito oriental el que concentra el mayor número de materiales, a pesar ser el más afectado por las reutilizaciones posteriores. En este recinto superior los materiales se concentran en una proporción del 90\%, hecho que contrasta con el escaso volumen (10\%) de materiales recuperados en el recinto inferior.

\section{MATERIALES, CUANTIFICACIÓN Y MÉTODO DE ANÁLISIS}

El estudio de los materiales en la fortaleza de Mendikute fue uno de los objetivos prioritarios desde el inicio de los trabajos dadas las características del yacimiento, con presencia constante de fuertes alteraciones estratigráficas fruto de la reutilización de espacios en época moderna y contemporánea. En este sentido, la recuperación de los objetos muebles presentes en la estratigrafía fue exhaustiva mediante el cribado de todo el depósito con malla de $5 \mathrm{~mm}$. A pesar de que la operación ralentizó notablemente la marcha de los trabajos de excavación, se mostró muy efectiva especialmente en el análisis de depósitos sueltos formados a partir de acciones contemporáneas sobre el emplazamiento, así como otros estratos densos y cenicientos que obstaculizaban la localización del material. De esta forma, fue posible localizar algunos hallazgos que por sus dimensiones o color hubieran pasado fácilmente desapercibidos, como es el caso de pequeños dados, piezas de orfebrería o monedas, entre otros.

El conjunto de objetos recuperados durante las seis campañas de excavación que se llevaron a cabo suma 1502 hallazgos. Con todo, cabe advertir que el inventario general acoge todos los materiales recuperados en el yacimiento, a excepción del material óseo, cuyo número -alrededor de 50.000 fragmentos- y volumen es extraordinariamente cuantioso. Se inventariaron, por tanto, los fragmentos de material óseo identificados como elementos reutilizados, es decir, aquellos con síntomas inequívocos de su manipulación antrópica y el resto se reservó para un estudio especializado (ORRI, 2000). Al margen de esta salvedad, y teniendo en consideración que el conjunto restante constituye únicamente un $5 \%$ a lo sumo del total, el análisis cuantitativo de estos elementos se ha llevado a cabo sin selección previa, incluyendo también en el cómputo aquellos materiales fechados de época moderna y contemporánea, fruto de las reutilizaciones sucesivas del asentamiento.

El objeto fundamental de nuestro análisis es el mobiliario medieval recuperado en la fortaleza, que constituye un $90 \%$ del conjunto inventariado. El 10\% restante lo conforman ejemplares en su mayoría metálicos que corresponden a restos de munición procedentes de la ocupación militar del recinto en los años de la Guerra Civil. Entre ellos se cuentan casquillos o vainas para mosquetón (38\%), fabricadas en Toledo y Madrid (ÁLVARO, 2000: 119), y algunos casquillos de munición para arma corta (8\%) junto con restos de cargadores (25\%) y algunas monedas (5\%). Al margen de algunos elementos plásticos sin mayor trascendencia para el estudio del asentamiento (24\%), solamente una pieza contemporánea responde a material lítico. Nos referimos a un pedernal con retoques marginales, cuya forma cuadrada y dimensiones nos permiten sugerir que se trata de una piedra de fusil (ÁLVARO, 2000: 120).

Los materiales de época medieval, datados en su mayoría de los siglos XIII y XIV a partir del numerario recuperado, constituyen un repertorio variado de especial interés para el conocimiento de la actividad cotidiana de una guarnición de frontera (Fig.5). La clasificación general del conjunto se ha llevado a cabo en base a la naturaleza de los materiales, definiendo así los conjuntos de material metálico, cerámico, óseo y lítico, a los que se añade una única muestra de madera. El grupo de objetos de metal (85\%) constituye con creces el conjunto mayoritario relegando a un segundo plano los materiales cerámicos (10\%), óseos (3\%) 


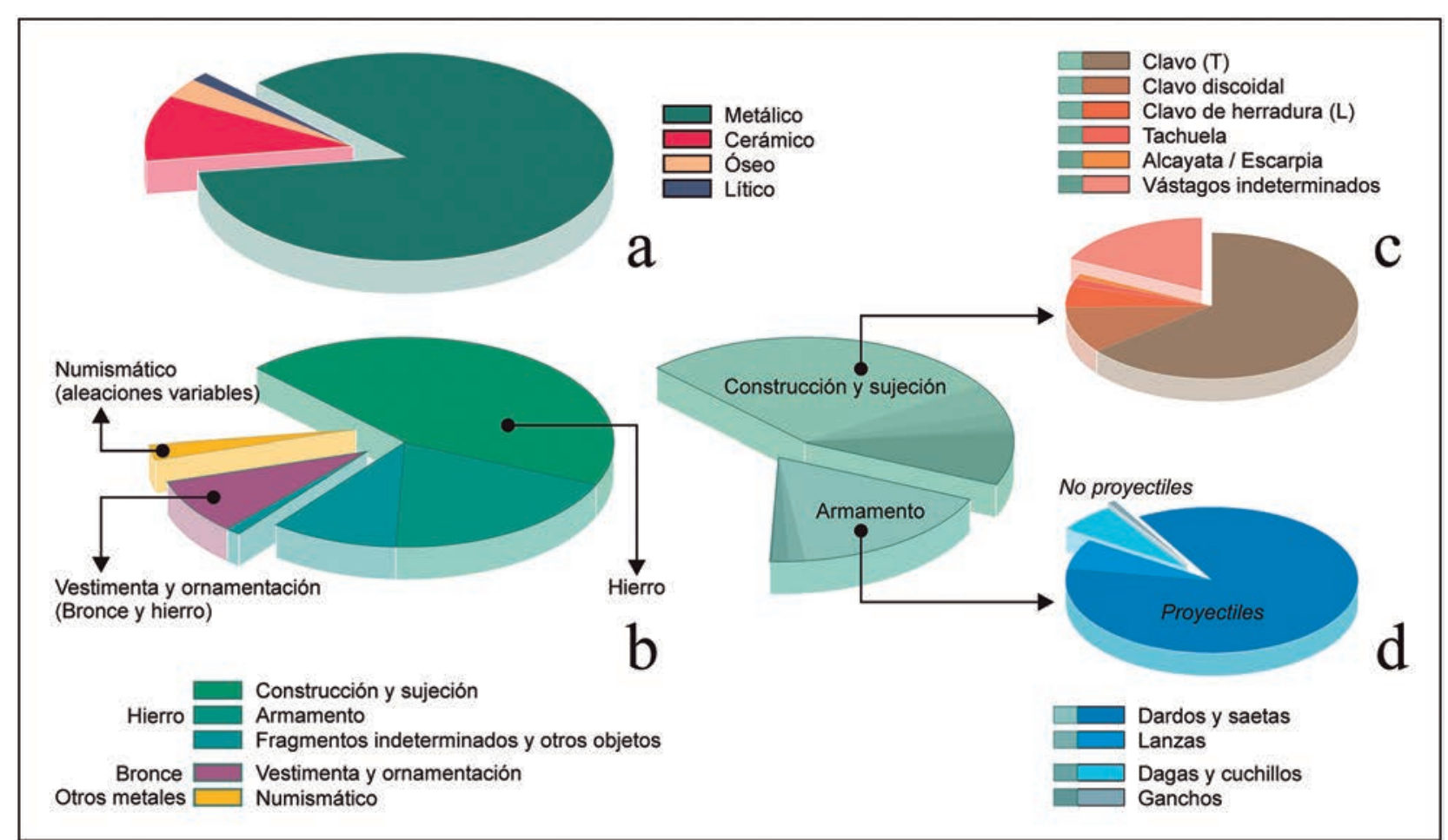

Fig. 5. Resultados del análisis cuantitativo practicado sobre los grupos inventariados: (a) distribución general de porcentajes en función de la naturaleza de los materiales, (b) distribución de los materiales metálicos en función de su naturaleza y tipo, (c) distribución de los elementos de construcción y sujeción, y (d) distribución de los principales tipos de armamento identificados. / Results of the quantitative analysis practiced on the inventoried groups: (a) percentage distribution of materials according to their nature, (b) distribution of metallic materials according to their nature and type, (c) distribution of building and fixing elements, and (d) distribution of main weaponry types identified.

y líticos (1\%). A la espera de poder ofrecer un análisis detallado de los materiales cerámicos, el conjunto de restos óseos incluidos en el inventario lo constituye un conjunto interesante de dados y elementos tallados en hueso que atestiguan la fabricación y uso de objetos lúdicos en el seno de la fortificación y que, por su singularidad, fueron objeto de un estudio pormenorizado, recientemente publicado (ÁLVARO et alii, 2017), a la luz de los paralelos existentes.

Entre el grupo de los metales, la clasificación general se ha realizado en base a dos variables: la naturaleza del metal (variable 1) y el tipo de objeto representado (variable 2). Así, contamos con un porcentaje elevado de piezas enteras o fragmentadas de hierro (87\%), un grupo menor de bronce (10\%) y un 3\% de aleaciones diversas que se corresponde íntegramente con el numerario recuperado en la excavación. Mientras que existe una correlación directa entre el porcentaje de monedas recuperadas y su clasificación en función de la naturaleza del metal; entre los conjuntos de hierro y bronce, se advierten algunas diferencias claras en relación con los principales objetos representados (Tabla I):

\begin{tabular}{|c|c|c|c|c|c|c|c|c|}
\hline \multirow{2}{*}{ Material } & \multirow{2}{*}{ Núm. } & \multirow{2}{*}{$\%$} & \multicolumn{6}{|c|}{ Material Metálico } \\
\hline & & & V.1: Naturaleza & Núm. & $\%$ & Variable 2: Tipo & Núm. & $\%$ \\
\hline \multirow{6}{*}{ Metálico } & \multirow{6}{*}{1020} & \multirow{6}{*}{85} & \multirow{4}{*}{ Hierro } & \multirow{4}{*}{888} & \multirow{4}{*}{87} & Construcción y sujeción & 528 & 52 \\
\hline & & & & & & Armamento & 228 & 22 \\
\hline & & & & & & Útiles diversos & 118 & 12 \\
\hline & & & & & & Vestimenta & 14 & 11 \\
\hline & & & Bronce & 103 & 10 & Vestimenta & 103 & \\
\hline & & & Otras aleaciones & 29 & 3 & Numerario & 29 & 3 \\
\hline Cerámico & 123 & 10 & & & & & & \\
\hline Óseo & 37 & 3 & & & & & & \\
\hline Lítico & 16 & 1 & & & & & & \\
\hline Vegetal & 1 & - & (madera) & & & & & \\
\hline
\end{tabular}

Tabla 1: Distribución cuantitativa del inventario de materiales de Mendikute en función de los datos absolutos y su porcentaje relativo para cada grupo o subgrupo determinado. / Quantitative distribution of Mendikute material register according to absolute data and relative percentages for each group or subgroup determined. 
El rasgo principal de los materiales de bronce y hierro es que los primeros se limitan exclusivamente a objetos de carácter ornamental relacionados con la vestimenta, generalmente hebillas o apliques, como tendremos ocasión de comentar, mientras que el material de hierro se destina a otro tipo de actividades. Ello no excluye que, entre el conjunto clasificado como vestimenta, se incluyan también algunas hebillas de este segundo material menos noble. Al margen de esta pequeña proporción de enseres para el atuendo, los elementos férricos responden principalmente a útiles para la construcción y sujeción (52\%), representados por un repertorio variado de clavos, tachuelas, escarpias o alcayatas, junto con un porcentaje considerable (20\%) de vástagos indeterminados; armamento $(22 \%)$ entre el que se cuentan puntas de flecha y lanza, fragmentos de cuchillos y dagas, entre otros; junto con un último grupo que incluye algunos objetos de uso cotidiano (12\%).

Todos estos elementos han sido documentados y sometidos a un análisis morfométrico, a fin de definir una tipología básica para cada conjunto en base a parámetros objetivos. Bajo esta óptica, el estudio del material óseo manipulado permitió identificar y analizar el proceso de fabricación de dados al que nos hemos referido con anterioridad (ÁLVARO et alii, 2017), y los trabajos en curso permitirán en breve aportar datos pormenorizados respecto del resto de materiales. Por ahora, debemos presentar de manera necesariamente preliminar una primera aproximación al conjunto.

\section{ELEMENTOS DE LA VIDA COTIDIANA EN UNA FORTALEZA MEDIEVAL}

La colección de materiales procedentes del yacimiento de Mendikute constituye un valioso ejemplo para ilustrar los principales elementos de uso cotidiano en una fortaleza medieval de frontera. Su distribución porcentual, con un conjunto de materiales cerámicos infra representados en relación a los metales o la fauna ponen de manifiesto la idiosincrasia propia del asentamiento. La representatividad del material cerámico puede ser incluso más reducida si tenemos en cuen- ta el parco grupo de formas representadas, por lo que será necesario ahondar en el análisis macroscópico y microscópico de las pastas a fin de proponer una interpretación plausible. Los elementos mejor conocidos, a pesar de su distribución variable, son los enseres propios del, vestido, armamento y actividades de construcción y de ocio de la soldadesca medieval en una escasa guarnición de frontera.

\subsection{Vestimenta y ornamentación}

Los objetos relacionados con el vestido son poco numerosos en el conjunto de la muestra y los hallamos preferentemente en bronce. Las hebillas, constituyen un grupo representativo, junto con distintos apliques de forma y dimensión variable, a menudo con decoraciones complejas labradas a cincel que, en algunos casos, parecen haber sido sobredoradas. El conjunto proporciona una muestra significativa de elementos ornamentales para el vestido o la armadura (Fig. 6).

En el grupo de hebillas de bronce (Fig. 6a) se pueden distinguir cuatro grupos básicos en función de su forma, bien representados por algunos ejemplares enteros (Tabla II). El primer grupo lo constituyen hebillas de traza rectangular, una de las cuales (12.215.1376) estuvo sobredorada; contamos también con piezas semicirculares; un único ejemplar circular y, finalmente, algunas hebillas de dimensiones algo mayores y forma arriñonada, en estos casos con restos de sobredorado. Cabe destacar la similitud de los dos ejemplares arriñonados, cuyas características sugieren un posible origen común de ambos.

En el grupo se incluyen algunas hebillas elaboradas en hierro o aleaciones de cobre, de factura indudablemente más sencilla y rasgos similares. Destaca en este sentido una hebilla de dimensiones algo mayores -casi 70 x 45 mm-, semiovalada y de sección rectangular (22.131.452) (Fig. 6b) que podríamos relacionar tal vez con el correaje de las caballerías. Una pieza análoga a ésta la encontramos en el Castello de Faria (Barcelos, Portugal) con unas dimensiones de 87 - 63 $\mathrm{mm}$ y datada con algunas reservas en el siglo XV. Se interpreta en este caso como una hebilla asociada a una

\begin{tabular}{|c|c|c|c|c|c|c|c|}
\hline \multirow{3}{*}{ Núm. Inv. } & \multirow{3}{*}{ Tipo } & \multirow{3}{*}{$\begin{array}{c}\text { Dimens. } \\
(\mathrm{mm})\end{array}$} & \multicolumn{4}{|c|}{ TRAVESAÑOS } & \multirow{3}{*}{ Observaciones } \\
\hline & & & \multicolumn{2}{|c|}{ Externo } & \multicolumn{2}{|c|}{ Interno } & \\
\hline & & & $(\mathrm{mm})$ & SEC.* & $(M M)$ & Sec. ${ }^{*}$ & \\
\hline 11.100 .0015 & Rectangular & $36 \times 15$ & 2 & $\mathrm{R}$ & 2 & $\mathrm{R}$ & Deformación del tavesaño interno \\
\hline 12.215 .1376 & Rectangular & $46 X--$ & 8 & 0 & - & $\mathrm{R}$ & Travesaño interno desaparecido \\
\hline 12.190.1192 & Semicircular & $32 \times 30$ & 11 & C & 4 & C & Restos de un pasador de hierro \\
\hline 12.240 .1437 & Semicircular & $29 \times 25$ & 5 & $\mathrm{H}$ & 3 & $\mathrm{R}$ & Sección hexagonal facetada \\
\hline 12.240 .1436 & Circular & $30 x--$ & 4 & C & 3 & C & Pseudocircular con caras planas \\
\hline 11.111 .0298 & Arriñonada & $30 \times 28$ & 7 & $\mathrm{~T}$ & 3 & $\mathrm{R}$ & Restos de sobredorado \\
\hline 11.111 .0132 & Arriñonada & $58 \times 27$ & 5 & $\mathrm{~T}$ & 3 & $\mathrm{R}$ & Sobredorada.Fina orla cincelada \\
\hline
\end{tabular}

Tabla 2: Clasificación y características morfométricas de los principales tipos de hebilla de bronce recuperados en el yacimiento. / Classification and morphometric features of the main bronze buckles discovered at the site. 


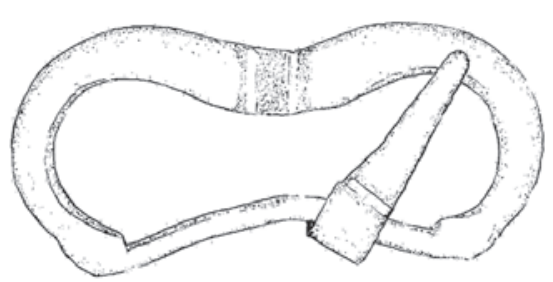

11.111 .132

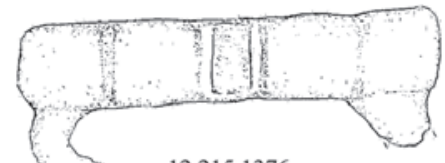

12.215 .1376
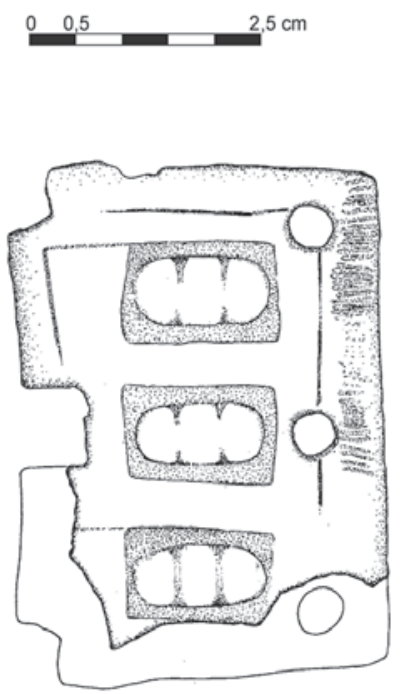

11.110 .133

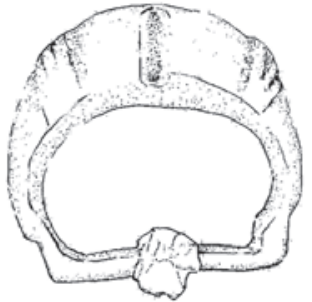

12.190 .1192

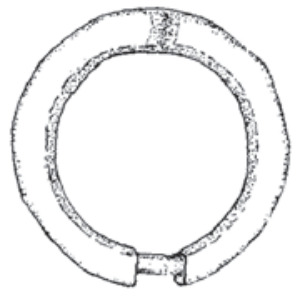

12.240 .1436

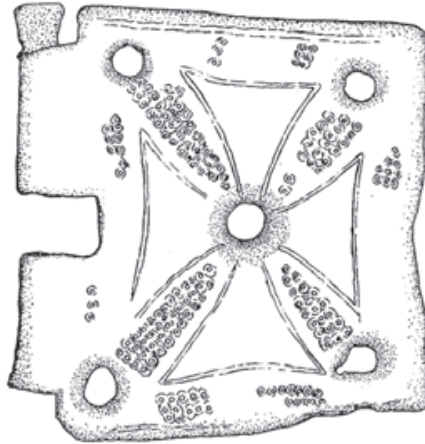

a
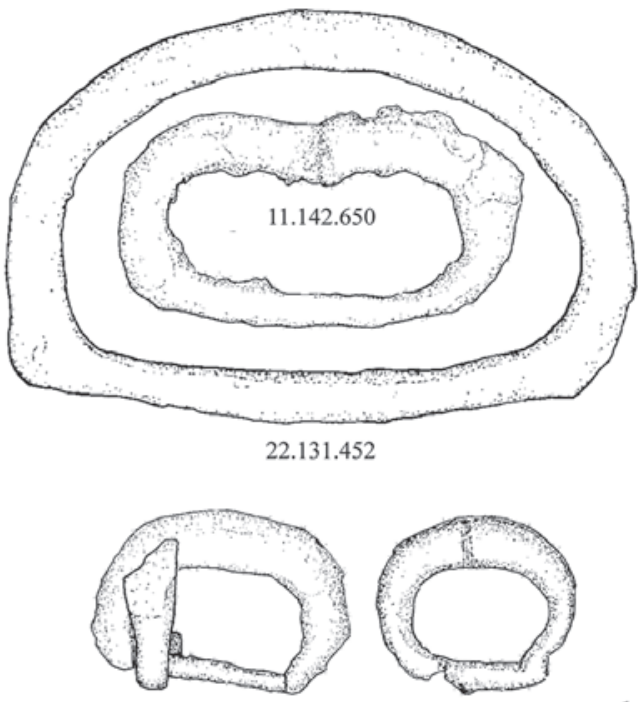

12.190 .1193

11.111 .177

b
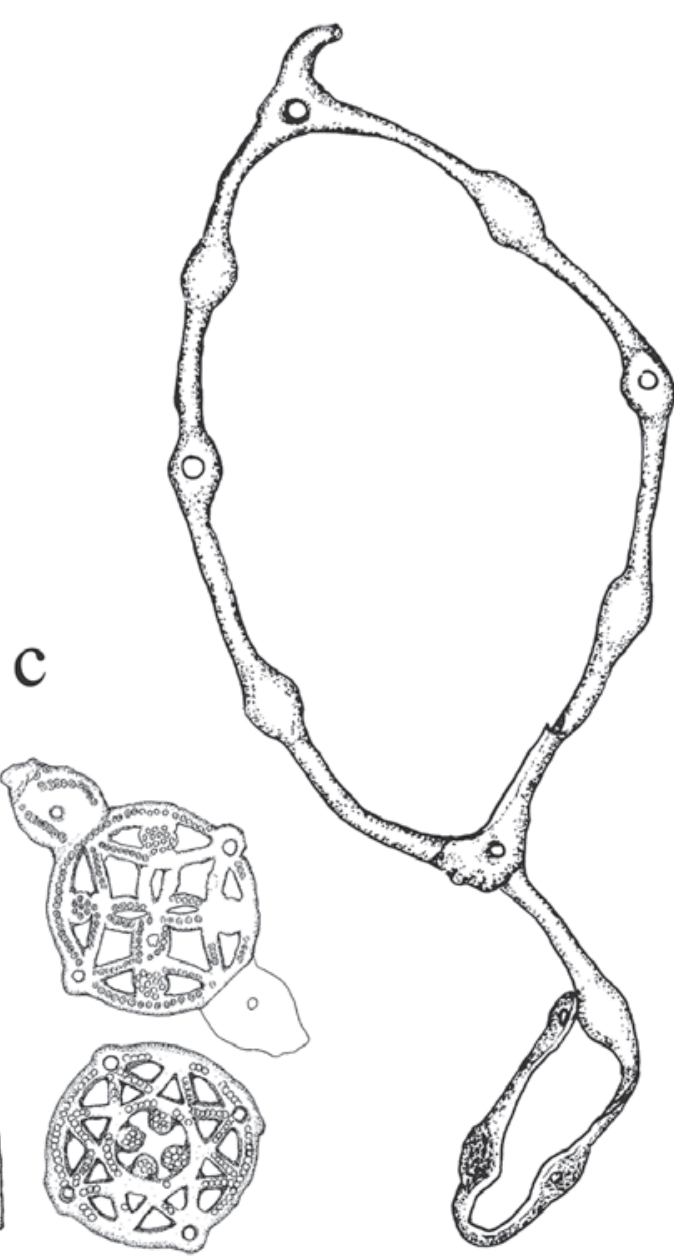

12.240 .1428

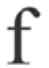

Fig. 6. Enseres para el atuendo y elementos ornamentales: (a) hebillas de bronce y (b) de hierro, (c) plaquitas decoradas de bronce, (d) aplique estrellado, (e) pequeños apliques rectangular y cuadrado, y (f) aplique de cinta./ Objects for cloths and embellishment: (a) bronze and (b) iron buckles, (c) decorated bronze clamps, (d) star-shaped applet, (e) small squared and rectangular applets, and (d) linear applet or collar. 
correa de cuero para una silla de montar (BARROCA Y GOUVEIA, 2000: 43, 306).

No existen paralelos directos para los tipos de hebilla de bronce localizados en Mendikute. Las formas más sencillas, como la hebilla de traza circular están presentes en otros conjuntos, aunque no se asocian directamente con los ejemplares presentes en la fortaleza de Mendikute. Las hebillas de traza circular y algunas piezas semicirculares procedentes de Rougiers (Var) datan del siglo XIII o primera mitad del XIV (DEMIANS D'ARCHIMBAUD, 1980: 483). En nuestro caso, pensamos que el conjunto de piezas parece acoger producciones de ámbito regional. Los paralelos más cercanos por cronología y tipología se encuentran entre los hallazgos descubiertos en el Túnel de San Adrián (Gipúzcoa-Álava) (GARCÍA 1987: 355-497).

Las placas de cinturón (Fig. 6c) son otro elemento habitual en el conjunto de materiales destinados a la ornamentación del vestido. Habitualmente en bronce, y alguna otra aleación del cobre, el repertorio de Mendikute cuenta con una placa cuadrada (12.190.1196), sobredorada, decorada con una composición pseudofloral de cuatro pétalos que enmarcan los cinco remaches de sujeción. Destaca también un ejemplar de hierro (11.110.133) de forma rectangular, repujado y con decoración simétrica. Algunas otras piezas de este grupo presentan restos de dorado con cenefas senciIlas, cinceladas alrededor de los bordes. Paralelos cercanos a estas piezas decoradas los hallamos también en el conjunto recuperado en el Túnel de San Adrián (Gipuzkoa-Álava) o en el yacimiento próximo del Alto de Surbi (Allarán, Álava) (GARCÍA 1987: 427, 467).

La muestra de apliques decorativos es bastante extensa, la mayoría de ellos fabricados en bronce o alguna otra aleación de cobre. La variedad de ejemplares fragmentados impide su sistematización precisa y no todos ellos parecen destinados a la guarnición del vestido o correajes sino también al ornato del mobiliario. Destaca un aplique decorativo de forma estrellada (Fig. 6d), formado a partir de una pequeña placa cuadrada de $26 \mathrm{~mm}$, desde cuyo centro, realzado en relieve y con perforación central, surgen cuatro puntas con una perforación en cada una de ellas.

Debemos destacar también algunas placas decoradas, que aparecen repujadas y sobredoradas y en las que se aprecia una representación animal (león o dragón) pasante a izquierda (Fig. 6e). Dos ejemplares rectangulares de características similares, mostrando un grifo rampante a izquierda aparecieron entre los materiales exhumados en el yacimiento de Montségur (L'Ariège) (MONTSÉGUR, 1980: 105). Junto a estas plaquitas, debemos mencionar también una pequeña serie de apliques calados, al parecer de carácter seriado. Los ejemplares de este grupo presentan un diseño circular, en ocasiones con apéndices laterales para su fijación, y diseños centrales que recuerdan los nudos de Salomón (12.240.1435). Algunos fragmentos análo- gos fueron hallados también en las inmediaciones del castillo de Murutegui (Álava) (GARCÍA, 1987: 464) o en la villa fortificada de Rougiers (Var) (DEMIANS D'ARCHIMBAUD, 1980: 519).

Hay que señalar también la presencia de una amplia serie de apliques rectangulares de pequeñas dimensiones decorados con aspas o cruces de San Andrés, todos ellos repujados, sobredorados y con perforaciones laterales para su fijación. Las dimensiones y similitud de todas estas piezas parecen indicar que se formaban parte de un mismo elemento. Junto a estos, cabe destacar también diversos apliques filiformes (Fig. 6f) o en forma de cordón, con ovas en relieve. El número de piezas no permite intuir el destino de estos elementos decorativos, que presentan en ocasiones algunas perforaciones para situarlos en alguna especie de soporte. La distancia existente entra cada una de las perforaciones sugiere que el soporte fuera rígido, por lo que cabría desmarcarlos como apliques decorativos de correajes.

\subsection{Armamento}

El repertorio de materiales férreos de época medieval localizado en la fortificación Mendikute incluye un nutrido grupo de elementos propios del armamento y demás accesorios de carácter bélico. El conjunto asciende a 228 piezas y está formado por elementos proyectiles, entre los que se incluyen puntas de lanzas (7\%) y de flecha (85\%), y no proyectiles, generalmente dagas o cuchillos (7\%), así como dos ejemplares de ganchos para armar la ballesta (Fig. 7). El estudio de este conjunto debe realizarse en base a una aproximación morfométrica detallada que permita precisar los principales tipos que parecen advertirse para cada uno de los elementos del repertorio bélico, por lo que ofrecemos a continuación una descripción preliminar de los principales grupos identificados. El conjunto de proyectiles está representado por las saetas o puntas de flecha y las lanzas o jabalinas.

Las flechas o saetas son especialmente numerosas, como se puede observar (Fig. 5d), pero su variabilidad tipológica no parece a priori demasiado elevada. Al contrario, conforman un conjunto bastante homogéneo con predominio de las formas piramidales de sección cuadrada y traza romboidal, con un ligero estrangulamiento en su unión con el cuerpo del enmangue. Las dimensiones de este, siempre tubular, parecen ser iguales o inferiores al desarrollo de la punta, apreciándose ligeras modificaciones de elaboración en la ejecución del mismo. Definir si su utilización se vincula al empleo del arco o de la ballesta, resulta muy complicado en ausencia de un análisis morfológico detallado. En cualquier caso, se trata de una forma que experimenta pocas variaciones, cuyos paralelos conocidos pueden remontarse hasta dos siglos (GONZÁLEZ, 2013) sin excesivos cambios morfológicos.

Los ejemplares de lanza o jabalina son menos numerosos, pero ofrecen en contrapartida una variabilidad 


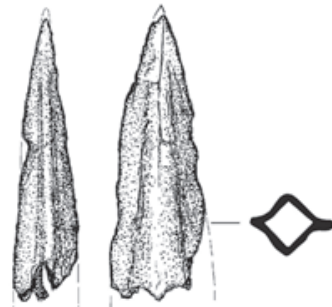

10.116 .634

12.220 .1309

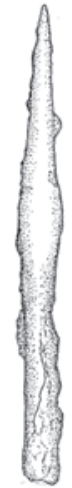

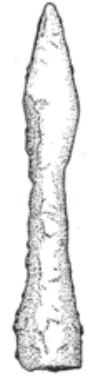

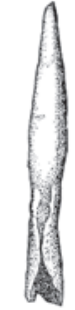

12.160 .704
11.111 .112

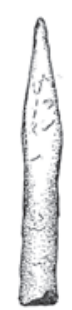

11.111 .79

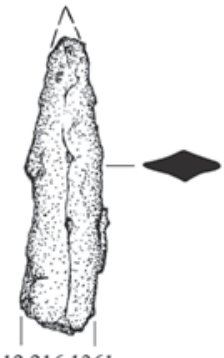

12.216 .1361

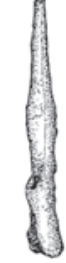

b
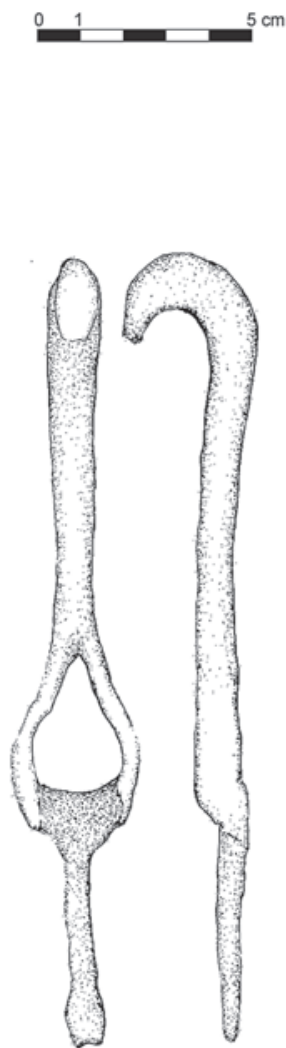

12.191.1237

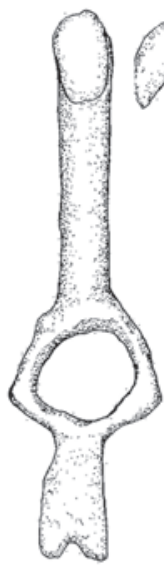

11.111.164

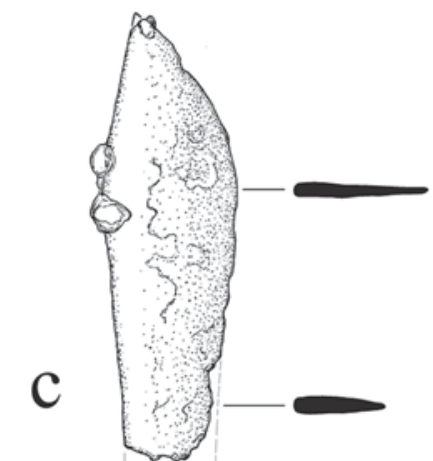

12.190 .1125
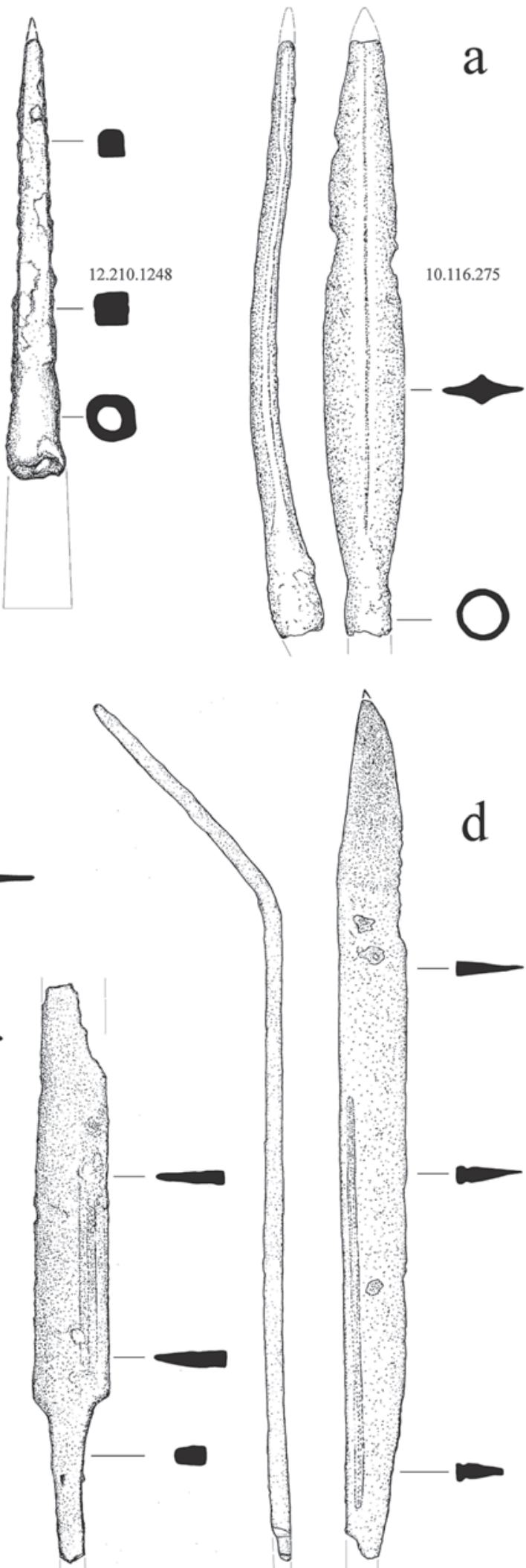

15.100 .92

Fig. 7. Principales tipos de armamento recuperados: (a) lanzas y puntas de lanza, (b) dardos opuntas de flecha, (c) hoja de cuchillo y (d) de dagas, y (e) ganchos para armar la ballesta. / Main weaponry elements discovered: (a) lances and spearheads, (b) darts and arrowheads, (c) knife blade, (d) dagger blades, and (e) hooks to arm a crossbow. 
algo mayor que puede ser contrastada con numerosos paralelos coetáneos. La mayoría de los ejemplares recuperados en Mendikute son piezas de grandes proporciones, con enmangue tubular para su inserción en el asta. Algunos de los ejemplares presentan sección maciza, pero también los hay de sección hueca, con pronunciados nervios axiales que revelan un procedimiento tecnológico de elaboración muy preciso (Fig. 7a). La disposición estratigráfica de estas armas indica que todas ellas son coetáneas, ya que las distintas formas conviven en niveles de utilización similares; por ejemplo, en un depósito que corresponde a la utilización de un pavimento de finales del siglo XIII o principios del XIV (UE 10.116) o bien en un contexto ligado a la última fase del área de cocina de la guarnición (UE 12.210) datado de la primera mitad del XIV, fechas que asumimos, por ahora para todos los materiales de este grupo.

El grupo constituido por el armamento no proyectil incluye dagas y cuchillos de hoja corta, así como dos ganchos para ballesta, que constituyen un atractivo interesante de la muestra. El armamento ofensivo altomedieval estaba compuesto en esencia por espadas, lanzas y arquería, pero desde mediados del XI se producen cambios sustanciales ante la generalización de la montura y el nuevo uso dado a las lanzas (CANTOS, 2017). La espada recta de doble filo será de uso predominante en plena Edad Media y, sin embargo, no se ha recuperado ningún ejemplar de este tipo en el yacimiento. Al contrario, en Mendikute se han recuperado algunos fragmentos de daga o espada corta, con hojas de un solo filo y un vástago para su enmangue y algunos cuchillos, fragmentados en todos los casos, que además de cumplir con una función ofensiva habrían fun- cionado también como instrumento doméstico para satisfacer otras necesidades cotidianas de la guarnición.

Existen numerosos paralelos para ilustrar el repertorio bélico entre los materiales recuperado en Alarcos (ZOZAYA, 1995), la alcazaba de Mértola (Barroca y Gouveia, 2000), y en el entorno europeo, en Rougiers (Var) (DEMIANS D'ARCHIMBAUD, 1980) y Montségur (L'Ariège) (MONTSÉGUR, 1980). Sin embargo, los paralelos más cercanos se hallan en la zona cercana al yacimiento, con casos muy evidentes en la necrópolis de Aldaita (Nanclares de Gamboa, Álava) (AZKARATE, 1999) y en la fortaleza vecina de Aitzorrotz (Escoriaza, Gipuzkoa) (BARANDIARAN, 1970), con dataciones muy similares, de finales del XIII y primera mitad del XIV.

\subsection{Elementos de construcción y sujeción}

Incluimos en este grupo los clavos, en sus distintas versiones y también un conjunto de elementos de sujeción -más ornamental que efectiva- vinculados al mobiliario de la fortaleza y a la decoración más o menos suntuaria de arcones y otros muebles. Se trata de un conjunto de tachones o tachuelas que por sus características merecen una atención especial (Fig. 8).

Los clavos constituyen el objeto más representado de todo el material inventariado. La muestra, que suma más de la mitad del conjunto de materiales metálicos recuerda, inevitablemente, el empleo masivo de la madera en el interior de estas fortificaciones, no sólo en las estructuras de cubierta y voladizos propios de este tipo de construcciones, sino también de la compartimentación interna del recinto. El medio millar de ejemplares
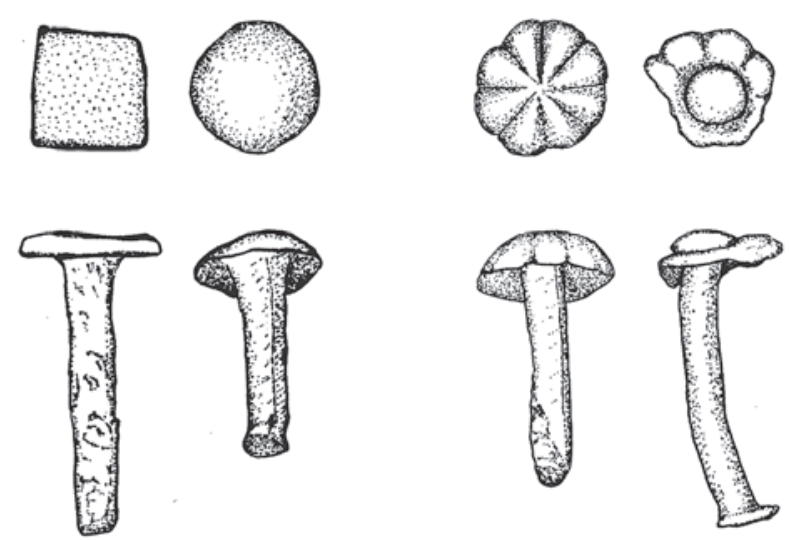

12.240 .1431

22.119 .518

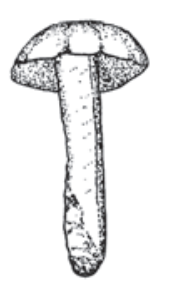

$12.240-1430$

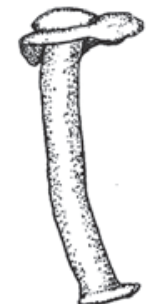

11.111 .116
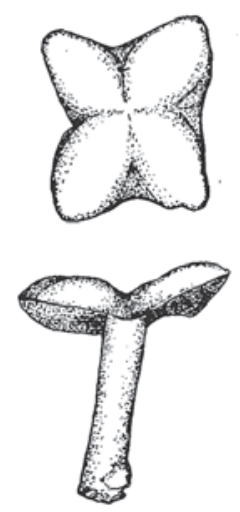

11.111 .191
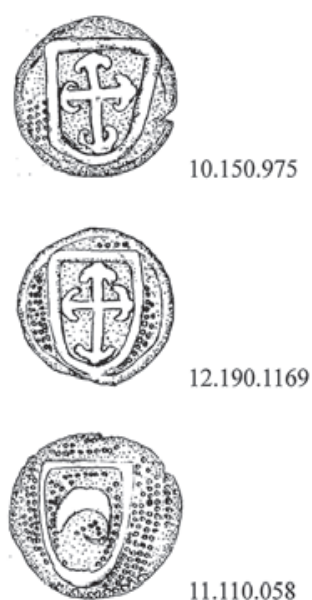

11.110 .058

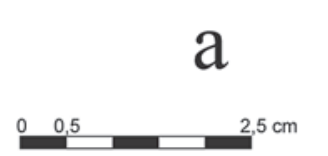

b
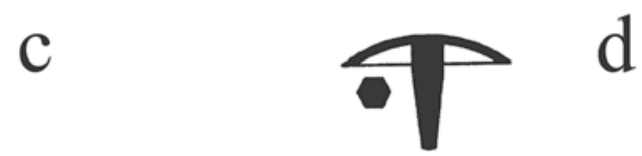

Fig. 8. Distintos tipos de tachuelas y tachones ornamentales de hierro: (a) sencillos de cabeza cuadrada o circular, (b) geométricos o florales, (c) floral de vástago corto, o (d) discoidales con motivos decorativos complejos grabados sobre su superficie. / Different types of iron embellishing tacks: (a) simple squared- or circular-headed tacks, (b) geometrical or floral, (c) floral with short stem, or (d) discoid with complex decoration engraved on the disc top. 
recuperados presenta algunas formas preferentes, en forma de T o con cabeza discoidal, entre otros, y numerosos vástagos de clasificación indeterminada por carecer de cabeza.

El clavo de forja que convenimos en denominar de tipo T, por su forma característica, está formado por un vástago y cabeza ambos de sección rectangular con una longitud media que oscila alrededor de los $80 \mathrm{~mm}$. Junto a este grupo, que constituye un $64 \%$ del total, se cuentan también clavos de forja de cabeza discoidal (10\%) con un diámetro entrono a los 5 mm y un vástago de sección cuadrada. Este grupo, presenta una longitud media ligeramente superior, que alcanza los 90 $\mathrm{mm}$. En el conjunto de los clavos se incluyen también los destinados al herraje de las monturas (5\%), con una cabeza engrosada de forma cuadrada o rectangular. Los ejemplares conservados tienen una dimensión media alrededor de los 30-35 mm, por lo que podríamos suponer en la mayoría de casos que habrían alcanzado los $40 \mathrm{~mm}$ de longitud.

El conjunto lo completan algunos ejemplares de clavos de tipo tachuela y alcayata, estos segundos en forma de L, de cuerpo cilíndrico y con un resalte a modo de aleta lateral. Las tachuelas, tachones o pernos recuperados se relacionan claramente con la ornamentación del mobiliario y otros objetos que presentan un repertorio variado. Las más sencillas presentan cabezas de forja sencilla cuadrada o circular (Fig. 8a), y algunas algo más complejas con motivos geométricos (Fig. 8b) o florales (Fig. 8c). Junto a ellas, otros tachones, con cabeza de sección semicircular y vástago algo más corto, aparecen adornados con escudetes, o motivos pseudoheráldicos y presentan únicamente dos moti- vos decorativos reiterados (Fig. 8d): sobre el campo un creciente tumbado en el primer caso, y una cruz latina con extremos terminados en flor de lis en el segundo. Este motivo flordelisado recuerda algunas de las acuñaciones reales francesas de época contemporánea, por lo que no sería extraño que hubiera que buscarse un origen francés para estos ejemplares (ROUDILLON Y DELAUNAY, 2015: 4).

\subsection{Otros elementos de uso cotidiano}

La utilización del material metálico recuperado en Mendikute queda bien circunscrita a las categorías propuestas hasta ahora -vestimenta, armamento y construcción- que incluyen el mayor porcentaje de elementos. Sin embargo, durante la vida útil de la fortificación se emplearon también otros enseres, en hierro y materiales diversos (hueso y cerámica) relacionados con actividades cotidianas de índole diversa. Dos instrumentos de hierro aparecen claramente relacionados con el ganado y las caballerías. Nos referimos en primer lugar a un cencerro de forma rectangular (Fig. 9a), con amplios paralelos en los yacimientos emblemáticos de Montségur (L'Ariège) (MONTSÉGUR, 1980: 167) y Rougiers (Var) (DEMIANS D'ARCHIMBAUD, 1980: 455), pero también en otros asentamientos peninsulares como el Despoblado de Rada (Navarra) (JUSUE, 1990: 360-361). Nuestra pieza, que aparece en contextos fiables, se encuentra entre los ejemplares de formato mediano, utilizados tanto por ganado mayor como menor. También en relación con el ganado, ha sido hallado un fragmento de hierro probablemente identificable con el estribo del arnés de una montura (Fig. 9b).

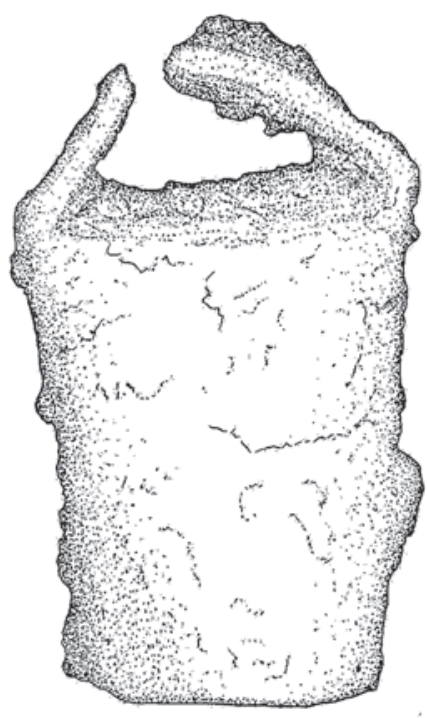

12.190 .1178 a

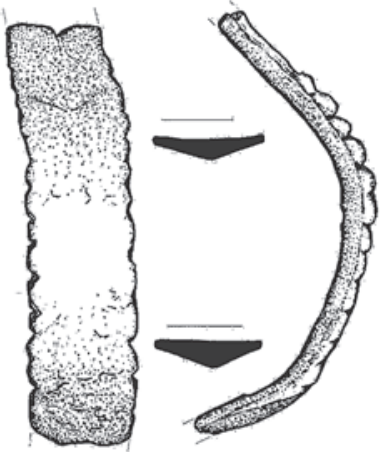

10.155 .657

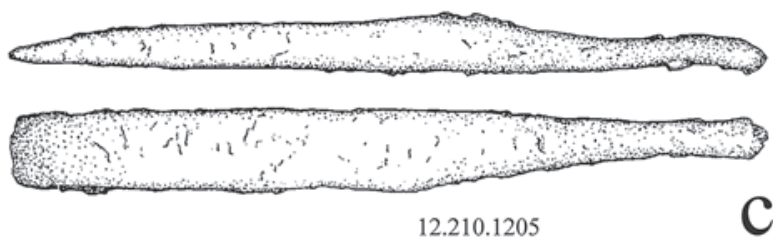

12.210 .1205

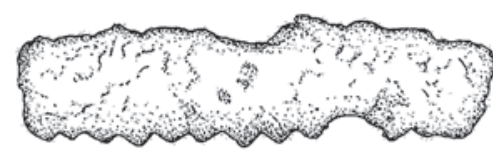

11.142 .433

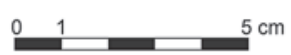

Fig. 9. Objetos de uso cotidiano forjados en hierro: (a) cencerro, (b) fragmento de un estribo, (c) cincel, y (d) hoja de sierra. / Daily iron worked objects: (a) cowbell, (b) stirrup fragment, (c) chisel and (d) saw blade fragment. 
Otro instrumento que aparece en contextos fiables de finales del siglo XIII y principios del XIV es un cincel de cuerpo de sección rectangular, extremo aguzado en bisel y un sólido vástago para su enmangue. El aspecto de la pieza, con unas dimensiones de 162 × $16 \mathrm{~mm}$, parece relacionarlo con el trabajo de talla de la madera o la piedra. Estas actividades cotidianas de los soldados también quedan atestiguadas por una lámina de hierro dentada -tal vez una sierra- que nos recuerda a los ejemplares análogos de instrumentos para el trabajo de la madera recuperados en las excavaciones de Montségur, especialmente el ejemplar 56/70 (MONTSÉGUR, 1980: 201), y también otros ejemplares de Rougiers de la misma cronología (DEMIANS D'ARCHIMBAUD, 1980: 459).

Al margen de los materiales metálicos, los elementos en hueso reutilizado (Fig. 10) constituyen una de las aportaciones más interesantes del conjunto, aunque su número es reducido. Este grupo está compuesto por una serie de piezas de enmangue o cachas, pomos o algún badajo para cencerro. Sin embargo, la serie de objetos ligados al ocio y al juego nos permiten hacer algunas consideraciones destacadas al respecto. Nos referimos a la aparición de algunas piezas paralelepípedas trabajadas sobre huesos largos, que permiten reconstruir el proceso de elaboración de dados y fichas en el seno de la fortificación (Fig. 10a-b), probablemente para el entretenimiento de la soldadesca. El conjunto incluye seis dados -uno de ellos con puntuación errática, aunque no fraudulenta- y un peón o ficha de juego. Dichos elementos lúdicos han sido analizados en profundidad y objeto de un artículo que los presenta de forma pormenorizada en esta misma publicación (ÁLVARO et alii, 2017), por lo que no nos parece procedente redundar en sus características.

Añadimos a este conjunto un fragmento excepcional de cacha o mango realizado en nácar (Fig. 10e), que al parecer presentaba una serie de orificios cuatrilobulados. Es posible que aquéllos estuvieran rellenos con algún tipo de pasta coloreada que resaltara sobre el nácar. La pieza conserva un pequeño remache en su extremo que servía para su fijación al soporte. Pudo formar parte del mango de un cuchillo de pequeñas proporciones o de algún otro instrumento de cierta relevancia.

Finalmente, entre los enseres de uso doméstico, sorprende en cierta medida la escasez del material cerámico, que debería ser debidamente caracterizado -y lo será en los próximos meses- dados los avances que se han producido en los últimos años (SOLAUN, 2005). Los elementos cerámicos recuperados en el recinto noble aparecen en el sector 11 y son fragmentos
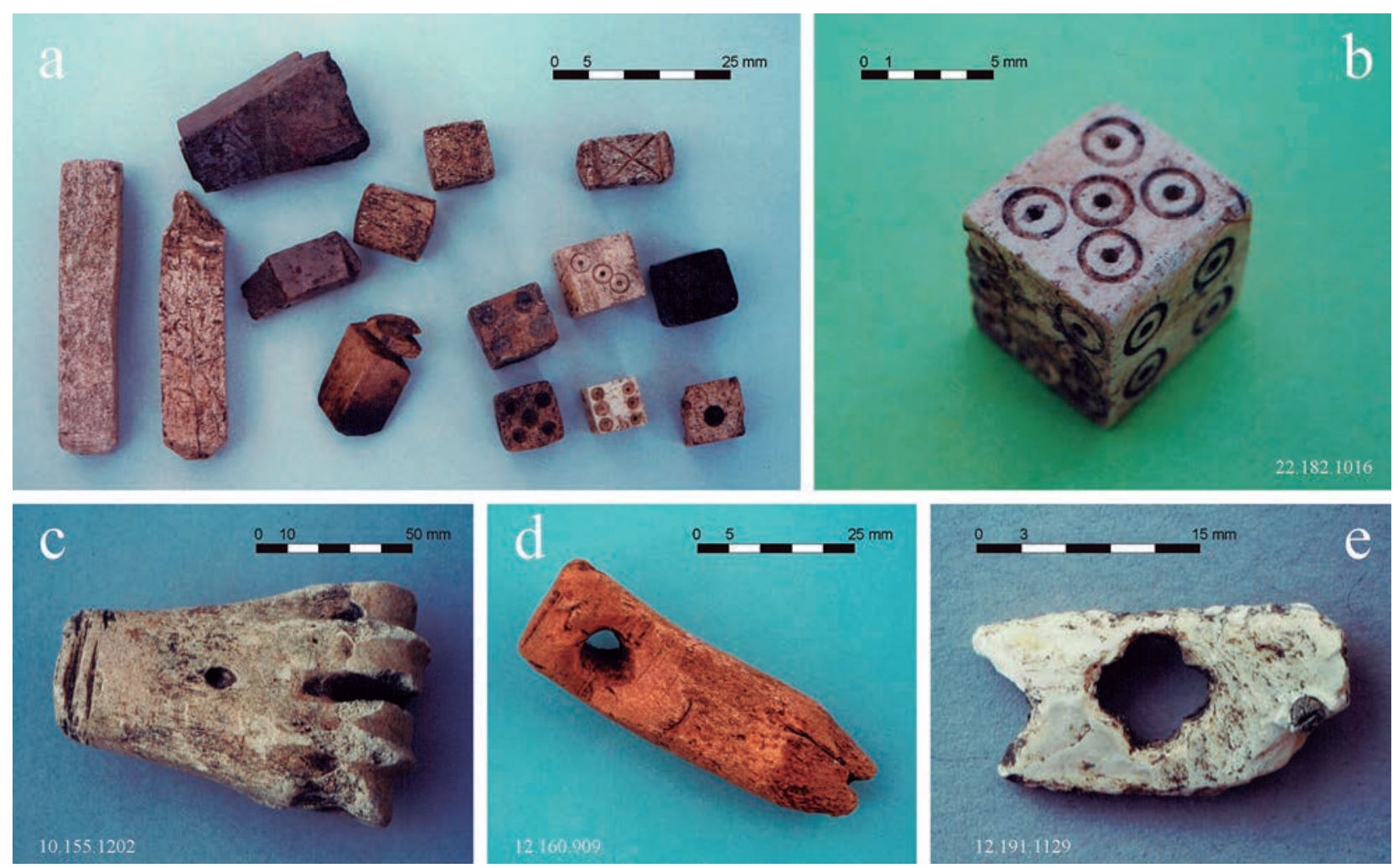

Fig. 10. Elementos óseos y faunísticos manipulados: (a) listones y regletas para la construcción de dados, fichas y peones, (b) dado tallado en asta, (c) fragmento de epífisis de bóvido con marcas de talla evidentes, (d) badajo para cencerro tallado en hueso, y (e) fragmento de una probable cacha de cuchillo tallada en nácar. / Bone and fauna manipulated materials: (a) bone bars for the fabrication of dice and game pieces, (b) horn-cut die, (c) bovine epiphysis fragment with evident cut marks, (d) bone-cutcowbell clapper, and (e) fragment of a probable knife handle cut in nacre. 
informes en su mayoría indeterminados, de pasta siena tostada a castaño, con inclusiones diminutas y fractura esquistosa, de cocción reductora. Junto a estos, existen algunas piezas con cubierta vidriada verde-ocre, de pasta oxidante y color pajizo. La escasa representatividad del repertorio cerámico sugiere la existencia de otro tipo de recipientes, tanto de madera como metálicos. Este aspecto, que parece ser habitual dentro de los yacimientos coetáneos del área septentrional del País Vasco, plantea algunas dificultades similares a las que podemos encontrar en la excavación y análisis de materiales procedentes de contextos altomedievales.

\section{DISCUSIÓN Y CONCLUSIONES}

El conjunto de materiales presentado ofrece un panorama sumario acerca de las principales actividades llevadas a cabo por los ocupantes de la guarnición fronteriza de Mendikute a lo largo de los siglos XIII y XIV. A pesar de los orígenes algo más tempranos de la fortificación, que parecen gestarse alrededor del siglo XI, los materiales parecen reflejar la fase final del periodo de ocupación medieval, afectado por las intervenciones de época contemporánea. Al margen del volumen ingente de restos óseos faunísticos, que fueron objeto de un análisis específico (ORRI, 2000), entre el conjunto de materiales inventariados, sin selección previa, destaca el volumen claramente predominante de los materiales metálicos, que atestiguan las actividades cotidianas llevadas a cabo en la fortificación.

La mayor parte de los enseres relacionados con la vestimenta y ornamentación los hallamos en el recinto noble, a excepción de algunos ejemplares muy escasos recuperados en el área inferior. No debe sorprendernos en este caso, que entre los materiales descubiertos en el recinto inferior se cuenten algunas de las hebillas de mayores dimensiones, que parecen corroborar el carácter relacionado con la guarda de las monturas atribuida a sector de la fortaleza. Las hebillas y apliques de sujeción con un carácter ornamental más o menos marcado en función de cada ejemplar, nos sugieren su empleo por parte de la soldadesca del lugar, que debió de lucir un atuendo más o menos ostentoso en base a alguna suerte de jerarquía interna.

Los restos pertenecientes a enseres bélicos también recuperados mayoritariamente en el recinto noble, aparecen distribuidos de manera bastante uniforme en todos los sectores intervenidos el área superior, a pesar de que el volumen mayoritario de dagas y cuchillos se recuperó en el ámbito oriental del área noble. A la espera de presentar una tipología detallada de los distintos elementos proyectiles y no proyectiles, en base a criterios cuantitativos de base morfométrica, el panorama general conocido hasta ahora nos permite hallar paralelos contemporáneos tanto en el área guipuzcoana como al otro lado de los Pirineos, en la fortaleza contemporánea de Montségur o el área marsellesa de Rougiers.
Los clavos, alcayatas, tachuelas y demás elementos de construcción y sujeción deben ser objeto de un análisis morfológico también pormenorizado en el futuro, dado que su volumen es el más cuantioso dentro del grupo de materiales metálicos y además, su homogeneidad interna y escasa variabilidad también son destacables. En este sentido, la aproximación morfológica a partir de una explotación estadística a partir del cómputo de dimensiones y la definición de tipos en este sentido también es una tarea pendiente para la investigación futura. El carácter suntuario de algunos de estos elementos vinculados a la ornamentación de distintos elementos que constituyeron el mobiliario de la fortaleza, ofrece algunas evidencias acerca de la jerarquización interna anteriormente mencionada.

La presencia de distintos elementos de uso cotidiano, habitualmente sin carácter ornamental alguno, como las herramientas de talla y labra tanto de la madera como de la roca ejemplificadas en la presencia de una hoja de sierra y un cincel, atestiguan las actividades de construcción y mantenimiento de las principales estructuras fortificadas. Junto a ellas algunos elementos propios del cuidado del ganado terminan de completar el conjunto. En cualquier caso, estos enseres cotidianos tampoco están exentos de la actividad creativa de sus productores, tal como nos demuestra la presencia de una cacha de nácar tallada y decorada.

Sin duda, hay dos elementos que destacan en el conjunto por su escasez y singularidad relativamente. El primero de ellos es el material cerámico, de carácter muy sencillo, seguramente para satisfacer unas necesidades cotidianas vinculadas a la manipulación y consumo de alimentos; actividad que no parece limitarse exclusivamente al uso de estos materiales. Así pues, el parco conjunto de enseres de cocina de cerámica, podría haber sido complementado otros elementos metálicos o tal vez por la presencia de utensilios de mesa probablemente de madera. El segundo elemento destacable lo constituyen el conjunto de restos óseos manipulados, que atestiguan una producción local de dados y elementos de carácter lúdico fabricados por la soldadesca, quizás durante las abundantes horas muertas en las que debieron emplearse los ocupantes del lugar.

Profundizar en las características de estos elementos materiales definiendo secuencias seriadas para los mismos y poniéndolas en relación con un registro estratigráfico exhaustivo debe aportar en los próximos meses algo más de luz en el conocimiento que aún hoy tenemos acerca de este territorio fronterizo que es Guipúzcoa a lo largo de los siglos XII y XIV.

\section{AGRADECIMIENTOS}

El trabajo presentado se cuenta entre las tareas habituales del Grupo de Investigación en Arqueología Medieval y Post-Medieval de la Universidad de Barcelona (GRAMP.UB), reconocido y consolidado por la Generalitat de Catalunya (2017SGR-833-GRC). Los trabajos arqueo- 
lógicos llevados a cabo desde los años noventa en la fortaleza medieval de Mendikute fueron posibles gracias a la realización de un proyecto titulado "Reorganización del espacio y estructura de poblamiento en la cuenca alta del río Oria (s. XI-XII, Guipúzcoa)", dirigido por el Dr. J. I. Padilla y financiado por la Diputación Foral de Guipúzcoa y el Gobierno Vasco, además del constante apoyo de la Sociedad de Ciencias Aranzadi durante toda la ejecución de dicho proyecto.

\section{BIBLIOGRAFÍA}

Adroher, A.M., Carreras, C., De Almeida, R., Fernández, R., Molina, J., Viegas, C., 2016. Registro para la cuantificación de cerámica arqueológica: Estado de la cuestión y una nueva propuesta. Protocolo de Sevilla (PRCS/14). Zephyrus 78, 87-110.

Álvaro, K., 2000. La Fortaleza Medieval deMendikute: Una aproximación al estudio de los materiales arqueológicos. Universidad de Barcelona. Departamento de Historia Medieval, Paleografía y Diplomática (Tesis de licenciatura inédita).

Álvaro, K., Travé, E., López, M.D., 2017. Los dados de Ausa y Mendikute (s. XIII-XIV): La elaboraciónde objetos lúdicos en hueso en algunas fortificacionesmedievales del territorio guipuzcoano. Munibe -Antropologia-Arkeologia 68, 273-288.

Arocena, F., 1957. El castrum Montis Acuti documentado como medieval. BRSVAP 13, 313-318.

Azkarate, A., 1988. Arqueologia cristiana de la Antigüedad tardía en Álava, Guipúzcoa y Vizcaya. Diputación Foral de Álava, Vitoria-Gasteiz.

Azkarate, A., 1999. Necrópolis tardoantigua de Aldaieta (Nanclares de Gamboa, Álava). Volumen I. Memoria de la excavación e inventario de los hallazgos. Diputación Foral de Álava, Vitoria-Gasteiz.

Azkarate, A., 2005. Sobre los orígenes cronológicos de los cementerios cispirenaicos de época tardoantigua. Munibe -Antropologia-Arkeologia 57, 405-417.

Barandiaran, I., 1970. Excavaciones de Aitzorrotz, 1968. Munibe 22(3-4), 125-174.

Barrena, E., 1989. La formación histórica de Gipúzcoa. Ed. Cuadernos Universitarios, 5. San Sebastián.

Barroca, M.J., Gouveia, J. (coord.), 2000. Exposición pera guerrejar. Armamento Medieval no Espaço Português. Câmara Municipal de Palmela, Palmela.

Cantos, A., 2017. El armamento y sus innovaciones en el Aragón de la segunda mitad del siglo XIV. Revista Universitaria de Historia Militar 6(11), 109-135.

Demians D'Archimbaud, G., 1980. Les Fouilles de Rougiers. Contribution a l'Archéologie de l'habitat rural médiéval en pays méditerranéen. Publicaction de l'U.R.A, 6. Archéologie médiévale méditerranéenne, Mémoires, 2. Éditions du CNRS, Paris.

García de Cortázar, J.A., 1988. Poblamiento y organización social del espacio vasco en la Edad Media. En: Congreso de Historia de Euskal Herria, Vol. 2, Instituciones, economía y sociedad (siglos VIII-XV), 421-444, Bilbao.

García Retes, E., 1987. El camino de San Adrián (Gipúzcoa-Álava) en la ruta jacobea. Análisis documental y arqueológico. Estudios de arqueología alavesa, Diputación Foral de Álava, Vitoria-Gasteiz.
Gónzález Castañón, M., 2013. El armamento de un asentamiento fortificado de finales del siglo XII: El Castro de los Judíos (Puente Castro, León). Miscelánea Medieval Murciana 37, 121-138.

Martinena, J.J., 1994. Castillos reales de Navarra (siglos XIII al XVI). Departamento de Educación y Cultura. Gobierno de Navarra, Pamplona.

Mauri, A., Travé, E., Del Fresno, P., 2012. An Integrated Implementation of Written and Material Sources - Conceptual Challenge and Technological Resources. In: Ollich, I. (ed.), Archaeology, New Approaches in Theory and Techniques, 4164. InTech, Croacia.

Mitxelena, K., 1953. Apellidos vascos. Biblioteca Vascongada de los Amigos del País, San Sebastián.

Orri, E. 2000. La Fortaleza medieval de Mendikute (Albitzur, Guipúzcoa): Una aproximación a los comportamientos alimentarios a través del análisis arqueozoológico. Universidad de Barcelona. Departamento de Prehistoria, Historia Antigua y Arqueología. (Tesis de licenciatura inédita).

Padilla Lapuente, J.I., 1992-7. Fortificación medieval de Mendikute (Albiztur). Arkeoikuska 92, 211-227; 93, 197-213; 94 , 185-203; 95,187-211; 96, 99-107; 97, 145-152. [Informes de campaña].

Roudillon, J. Delaunay, J., 2015. Medailles, monnaies. Collections. Rènnes Enchères.

Solaun, J.L., 2005. La cerámica medieval en el País Vasco (Siglos VIII - XIII). Colección de Patrimonio Cultural Vasco. Departamento de Cultura, Gobierno Vasco / Universidad del País Vasco, Vitoria-Gasteiz.

VVAA. Montségur, 13 ans de Recherche Archéologique. Groupe de Recherches Archéologiques de Montségur et Environs. Número spécial.

Zozaya, J. (coord.), 1995. Alarcos. El fiel de la Balanza. Junta de Comunidades de Castilla-La Mancha. Col. Patrimonio Histórico, 15. 